\title{
Angiotensin-(1-7) attenuates caerulein-induced pancreatic acinar cell apoptosis
}

\author{
LIJIAN CUI $^{1 *}$, RUIXIA LIU ${ }^{1 *}$, CHUNYUN LI $^{2}$, XIAOZHENG YU ${ }^{1}$, XIAOYA LIU ${ }^{2}$, \\ FEI HOU ${ }^{1}$, $\mathrm{CHENG} \mathrm{CHI}^{2}$, CHENGHONG YIN $^{2}$ and $\mathrm{CHAO}_{\text {WANG }}{ }^{1}$ \\ ${ }^{1}$ Department of Infectious Diseases, Beijing Friendship Hospital, Capital Medical University, Beijing 100050; \\ ${ }^{2}$ Department of Internal Medicine, Beijing Obstetrics and Gynecology Hospital, \\ Capital Medical University, Beijing 100026, P.R. China
}

Received August 18,2016; Accepted May 15, 2017

DOI: $10.3892 / \mathrm{mmr} .2017 .6982$

\begin{abstract}
Extensive apoptosis of pancreatic acinar cells frequently occurs in acute pancreatitis (AP), and has been identified to be closely associated with the decrease of pancreatic parenchymal cells and pancreatic damage. The present study aimed to investigate the possible effect of angiotensin (Ang)-(1-7) on caerulein (CAE)-induced pancreatic acinar cell apoptosis. Mouse pancreatic acinar cancer cells (MPC-83) were divided into 4 groups: Control group; CAE group; CAE + Ang-(1-7) group; and CAE + Ang-(1-7) antagonist (A779) group. The control group consisted of normal MPC-83 cells without special treatment. The CAE group was stimulated with $10 \mathrm{nmol} / 1 \mathrm{CAE}$ and harvested at 2, 6, 12, 24 and $48 \mathrm{~h}$. For the CAE + Ang-(1-7) group and CAE + A779 group, the CAE-induced pancreatic acinar cells were mock pretreated or pretreated with different concentrations of Ang-(1-7) or A779 $\left(10^{-7}, 10^{-6}\right.$ or $\left.10^{-5} \mathrm{~mol} / \mathrm{l}\right)$ for $30 \mathrm{~min}$. Caspase-3 is a critical
\end{abstract}

Correspondence to: Professor Chenghong Yin, Department of Internal Medicine, Beijing Obstetrics and Gynecology Hospital, Capital Medical University, 251 Yaojiayuan Road, Chaoyang, Beijing 100026, P.R. China

E-mail: modscn@126.com

Professor Chao Wang, Department of Infectious Diseases, Beijing Friendship Hospital, Capital Medical University, 95 Yongan Road, Xicheng, Beijing 100050, P.R. China

E-mail: 15910938286@163.com

${ }^{*}$ Contributed equally

Abbreviations: ACE, angiotensin-converting enzyme; ACE2, angiotensin-converting enzyme 2; ACE2-Ang-(1-7)-Mas, ACE2angiotensin-(1-7)-Mas; ACE-Ang II-AT1, angiotensin-converting enzyme-angiotensin II type 1 receptor; AP, acute pancreatitis; CAE, caerulein; DRs, death receptors; MPC-83, mouse pancreatic acinar cancer cells; RAS, renin-angiotensin system

Key words: angiotensin-(1-7), apoptosis, caspase-3, B-cell lymphoma 2, bcl-2-like protein 4, angiotensin-converting enzyme 2 , Mas receptor executioner of apoptosis, as it is either partly or completely responsible for the proteolytic cleavage of numerous key proteins including the nuclear enzyme poly (ADP-ribose) polymerase. Activation of caspase- 3 requires proteolytic processing of its inactive zymogen into activated p17 and p12 fragments. Thus, the present study investigated the apoptotic markers, including cleaved caspase-3, B-cell lymphoma 2 (Bcl-2), Bcl-2-like protein $4(\mathrm{Bax})$ and renin-angiotensin system (RAS) pathway related proteins (ACE2 and Mas receptor). The results demonstrated that the cleaved caspase-3 levels were increased in the CAE group $(\mathrm{P}<0.05)$, peaking at $24 \mathrm{~h}$, and declined when incubated with Ang-(1-7). Following treatment with Ang-(1-7), levels of the anti-apoptotic protein Bcl-2 rose dramatically in a dose-dependent manner. The ratio of the pro-apoptotic protein $\mathrm{Bax}$ to the anti-apoptotic protein Bcl-2 dropped notably, which demonstrated a tendency towards curbing apoptosis. In addition, the cleaved caspase-3 levels, and the ratio of $\mathrm{Bax}$ to $\mathrm{Bcl}-2$ in the $\mathrm{CAE}+\mathrm{A} 779$ group presented a significant rise compared with the CAE group. It was concluded that Ang-(1-7) may possess an inhibitory effect on CAE-induced pancreatic acinar cell apoptosis and that appropriate interventions in RAS may attenuate pancreatic injury during AP.

\section{Introduction}

Recent studies have demonstrated that pro-inflammatory mediators and pancreatic acinar cell apoptosis are involved acute pancreatitis (AP) (1-3). Apoptosis is characterized by distinct morphological and biochemical changes, including cytoplasmic shrinkage, retention of organelles, nuclear pycnosis, chromatin condensation and margination, in addition to retention of integrity of the plasma membranes, and thus no leakage of cellular contents to the extracellular environment (4). This programmed cell death is initiated in cells in response to either extracellular cues via stimulation of the death receptors (DRs), often referred to as the extrinsic pathway, or to a variety of intracellular stress conditions that involve mitochondria and is known as the intrinsic pathway (5). Certain members of the family of cysteine aspartases (caspases) function as part of the apoptotic pathway, and they are divided into initiators (caspases-2, -8, -9 and -10) and executioners (caspase-3, -6 and 
-7) (6,7). Caspase-3 is an executioner caspase, activated by the intrinsic and extrinsic pathways, which regulates the initial apoptotic process $(8,9)$. The B-cell lymphoma 2 (Bcl-2) family is another functional component in the apoptosis pathway and it is divided into pro-apoptotic [Bcl-2-like protein 4 (Bax), Bcl-2 homologous antagonist/killer and Bcl-2 related ovarian killer] and anti-apoptotic [B-cell lymphoma 2 (Bcl-2), Bcl-2-extra large, Bcl-2-like protein 2, myeloid cell leukemia sequence 1 and Bcl-2-related protein A1] groups (10). The outcome for a cell in receipt of an apoptotic stimulus is hypothesized to depend partly on the ratio of pro- and anti-apoptotic members of the Bcl-2 family (11). Therefore, cellular injury and apoptotic markers (cleaved caspase-3, Bcl-2 and Bax) were used in the present study to determine the degree of caerulein (CAE)-induced pancreatic cell apoptosis.

Previous studies have demonstrated that the classic angiotensin-converting enzyme-angiotensin II type 1 receptor (ACE-Ang II-AT1) axis activity increases and may aggravate the development of pancreatitis (12-14). Studies have demonstrated that ACE2-Ang-(1-7)-Mas [ACE2-Ang-(1-7)-Mas] axis, the non-classical and the depressor renin-Ang system (RAS) pathway, possess adverse effects in numerous diseases and may be therapeutically useful $(15,16)$. However, little is known about the potential roles of ACE2-Ang-(1-7)-Mas in apoptosis, and its precise method of regulation in any organ system. Various studies have demonstrated that Ang-(1-7) regulates alveolar epithelial cell survival by inhibiting c-Jun $\mathrm{N}$-terminal kinase phosphorylation and apoptosis through the Ang-(1-7) receptor Mas (17-20). Gaddam et al (12) identified that the Ang II to Ang-(1-7) ratio increased in the pancreas, suggesting dysregulation of RAS in AP as evidenced by altered Ang II/Ang-(1-7) levels induced by the imbalance of ACE/ACE2 activity. The purpose of the present study was to determine whether the activation of the ACE2-Ang-(1-7)-Mas axis possesses similarly positive effects on the digestive system, particularly in pancreatic inflammatory disease, as it exhibits its important function in the cardiovascular system.

\section{Materials and methods}

Cell culture. Mouse pancreatic acinar cancer cells (MPC-83; Cancer Institute \& Hospital, Chinese Academy of Medical Sciences, Beijing, China) were cultured in RPMI-1640 medium (Hyclone; GE Healthcare Life Sciences, Logan, UT, USA) supplemented with 10\% FBS (Gibco; Thermo Fisher Scientific, Inc., Waltham, MA, USA), $100 \mathrm{U} / \mathrm{ml}$ penicillin and $100 \mathrm{mg} / \mathrm{ml}$ streptomycin. Cells were incubated at $37^{\circ} \mathrm{C}$ in a humidified atmosphere containing $5 \% \mathrm{CO}_{2}$. All experiments were conducted with RPMI-1640 medium, with or without $10 \mathrm{nmol} / \mathrm{l} \mathrm{CAE}$, for varying time periods. Cells were cultured in culture bottles and petri dishes.

Cells in culture bottles were stimulated with $10 \mathrm{nmol} / \mathrm{l} \mathrm{CAE}$ (Sigma-Aldrich; Merck KGaA, Darmstadt, Germany) for the indicated time periods for AP (21), and the cells were divided into 4 groups: A, control; B, CAE; C, CAE + Ang-(1-7); and D, $\mathrm{CAE}+\mathrm{A} 779$ groups. Group A represented the normal growth of MPC-83 cells without stimulation. Group B cells were harvested at 2, 6, 12, 24 and $48 \mathrm{~h}$ subsequent to being induced by $10 \mathrm{nmol} / 1 \mathrm{CAE}$. Groups $\mathrm{C}$ and D, based on the dynamic test outcomes of Group B, it was identified that the expression of the cleaved caspase- 3 protein level reached its peak in cells stimulated by CAE at $24 \mathrm{~h}$, and the ratio of Bax and Bcl-2 reached its maximum at $6 \mathrm{~h}$ and remained relatively high at $24 \mathrm{~h}$ however declined over time. Considering the above, the MPC-83 cells in the CAE $24 \mathrm{~h}$ group (MPC-83 cells of the CAE group harvested at $24 \mathrm{~h}$ ) were selected for experimentation for groups $\mathrm{C}$ and $\mathrm{D}$. The cells were mock pretreated or pretreated with different concentrations of Ang-(1-7) or A779 $\left(10^{-7}, 10^{-6}\right.$ or $\left.10^{-5} \mathrm{~mol} / \mathrm{l}\right)$ for $30 \mathrm{~min}$ then were stimulated with $10 \mathrm{nmol} / \mathrm{l} \mathrm{CAE}$ for $24 \mathrm{~h}$. Finally, cells were harvested for western blotting.

The cultivation steps of the cells in the petri dishes were as described above. The harvested cells were seeded onto glass coverslips in 6-well plates at $1 \times 10^{5}$ cells/well for immunocytochemistry, with 3 wells for each group. These cells were used for immunofluorescence.

Immunofluorescence. Immunofluorescence staining was used to detect the presence of ACE2, Mas receptor, caspase-3, Bax and Bcl-2 in MPC-83 cells. Briefly, MPC-83 cells were rinsed in PBS ( $\mathrm{pH} 7.4 ; 138 \mathrm{mM} \mathrm{NaCl}, 2.67 \mathrm{mM} \mathrm{KCl}, 8.10 \mathrm{mM}$ $\left.\mathrm{Na}_{2} \mathrm{HPO}_{4}, 1.47 \mathrm{mM} \mathrm{KH} \mathrm{PO}_{4}\right)$ and fixed in $4 \%(\mathrm{v} / \mathrm{v})$ paraformaldehyde $\left(40 \mathrm{~min}, 37^{\circ} \mathrm{C}\right)$. Following fixation, the cells were blocked with $1 \%$ bovine serum albumin (Sigma-Aldrich; Merck KGaA) for $30 \mathrm{~min}$ at $37^{\circ} \mathrm{C}$. Then the cells were incubated with the following primary antibodies: Anti-ACE2 (1:200; cat no. ab59351; Abcam, Cambridge, MA, USA), anti-Mas receptor (1:100; cat no. AAR-013; Alomone Labs, Jerusalem, Israel), anti-caspase-3 (1:100; cat no. 9662; Cell Signaling Technology, Inc., Danvers, MA, USA), anti-Bax (1:100; cat no. bs-0127R) and anti-Bcl-2 (1:100; cat no. bs-0032R) (both from BIOSS, Beijing, China) at $4^{\circ} \mathrm{C}$ overnight. Goat anti-rabbit fluorescein isothiocyanate (green fluorescent; 1:100; cat no. bsF-0295G; BIOSS) probes were used as secondary antibody and the cells were incubated with the secondary antibody for $40 \mathrm{~min}$ at $37^{\circ} \mathrm{C}$. Then the cell nucleus was stained with DAPI $(1: 1,000$; Santa Cruz Biotechnology, Inc., Dallas, TX, USA) for $5 \mathrm{~min}$ at $37^{\circ} \mathrm{C}$. Immunofluorescence was performed by visualization under a motorized inverted system fluorescence microscope (Olympus IX81; Olympus Corporation, Tokyo, Japan). Cells incubated with normal rabbit serum (Sigma-Aldrich; Merck $\mathrm{KGaA}$ ) instead of a primary antibody served as a negative control.

Western blotting of ACE2, Mas receptor, cleaved caspase-3, $B a x$ and $B c l-2$. Cells were washed three times with cold PBS $\left(4^{\circ} \mathrm{C}\right)$, followed by lysing the cells on ice with lysis buffer [pH 7.5; $150 \mathrm{mM} \mathrm{NaCl}, 50 \mathrm{mM}$ Tris, $1 \mathrm{mM}$ phenylmethylsulfonyl fluoride, $1 \mathrm{mM} \mathrm{Na}_{3} \mathrm{VO}_{4}, 1 \% \mathrm{NP}-40,0.1 \% \mathrm{SDS}, 0.5 \%$ deoxycholic acid, $1 \%$ protease inhibitor cocktail (BIOSS)] for $30 \mathrm{~min}$. The total protein concentration was determined with a bicinchoninic acid protein assay kit (Pierce; Thermo Fisher Scientific, Inc.). Then the protein $(25 \mu \mathrm{g})$ was separated by $10 \%$ SDS-PAGE gel electrophoresis and transferred onto PVDF membranes, which were blocked with 5\% non-fat dried milk for $2 \mathrm{~h}$ at $37^{\circ} \mathrm{C}$ and incubated overnight at $4^{\circ} \mathrm{C}$ with rabbit anti-mouse ACE2 monoclonal antibody at 1:400 and mouse $\beta$-actin monoclonal antibody at 1:500 (cat no. ab3280; Abcam), rabbit anti-mouse Mas receptor polyclonal antibody at 1:200 (Alomone Labs) and rabbit anti-mouse caspase-3 monoclonal 
antibody at 1:800 (Cell Signaling Technology, Inc.), and rabbit anti-mouse Bax and Bcl-2 polyclonal antibody (1:200; BIOSS). All the antibodies were diluted in TBS containing $0.05 \%$ Tween-20 (TBST). Subsequent to washing three times with TBST, the membranes were subsequently incubated for $1 \mathrm{~h}$ at room temperature with peroxidase-conjugated goat anti-rabbit (1:8,000; cat no. sc-2004) or goat anti-mouse (1:8,000; cat no. sc-2031) (both from Santa Cruz Biotechnology, Inc.) secondary antibodies. The membranes were washed three times with TBST and enhanced chemiluminescence (Merck $\mathrm{KGaA}$ ) was used to detect immunoreactive protein bands. Blots were semi-quantified by densitometric analysis using Image Lab software version 3.0 (Bio-Rad Laboratories, Inc., Hercules, CA, USA).

Statistical analysis. All experiments were repeated at least 3 times independently. Data were expressed as the mean \pm standard deviation. Results were analyzed using SPSS software version 13.0 (SPSS, Inc., Chicago, IL, USA). The statistical significance of the differences between groups was assessed using two-way analysis of variance followed by post hoc Newman-Keuls test for multiple comparisons. $\mathrm{P}<0.05$ was considered to indicate a statistically significant difference.

\section{Results}

Localization of ACE2, Mas receptor, caspase-3, Bax, and Bcl-2 in MPC-83 cells. Because of its remarkable specificity, the immunofluorescence assay is a valuable method for making a definite diagnosis of the localization of ACE2, Mas receptor, caspase-3, Bax and Bcl-2 in MPC-83 cells. Immunofluorescence demonstrated that ACE2, caspase-3, Bax and Bcl-2 were present predominantly in the cytoplasm, while Mas receptor was identified predominantly in the membrane of the MPC-83 cells (Fig. 1).

Dynamic protein levels of the cleaved caspase-3, Bax and $B c l-2$ in CAE group. Western blotting analysis indicated that exposure to $10 \mathrm{nmol} / \mathrm{l} \mathrm{CAE}$ promoted cleaved caspase-3 expression, however suppressed $\mathrm{Bax}$ and $\mathrm{Bcl}-2$ protein levels $(\mathrm{P}<0.05$; Fig. 2A-C). It exhibited a significant evident increasing trend of the cleaved caspase- 3 protein level $(\mathrm{P}<0.05)$ and reached the highest value at $24 \mathrm{~h}($ Fig. $2 \mathrm{~B})$. The ratio of Bax and Bcl-2 increased in the CAE group compared with the control group and reached the highest value at $6 \mathrm{~h}$ (from $1.002 \pm 0.076$ to $2.079 \pm 0.216 ; \mathrm{P}<0.05$ ) then declined over time (Fig. 3D).

Protein profiles of ACE2, Mas receptor in CAE $24 \mathrm{~h}$ group. ACE2 and Mas receptor protein expression in normal MPC-83 cells was determined by western blotting, and quantified with Image Lab software version 3.0 (Fig. 3; Bio-Rad Laboratories, Inc.). ACE2 and Mas receptor protein levels were significantly increased (from $0.340 \pm 0.067$ to $1.222 \pm 0.142, \mathrm{P}<0.05$, and from $0.521 \pm 0.068$ to $1.165 \pm 0.112, \mathrm{P}<0.05)$ in the CAE $24 \mathrm{~h}$ group compared with the control group.

Ang-(1-7) effects on the levels of the cleaved caspase-3, Bax and Bcl-2. To determine whether Ang-(1-7) has positive effects on apoptosis, MPC-83 cells of the CAE group were

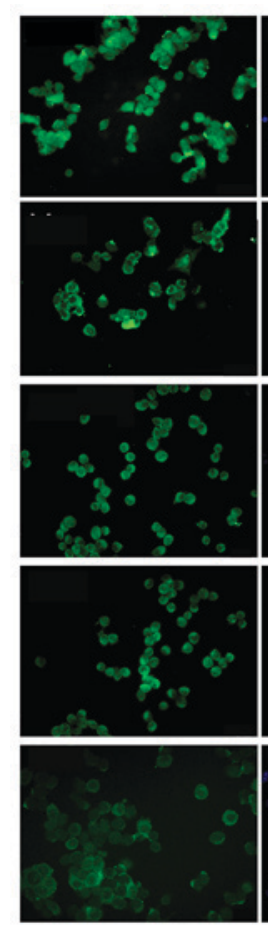

Target protein
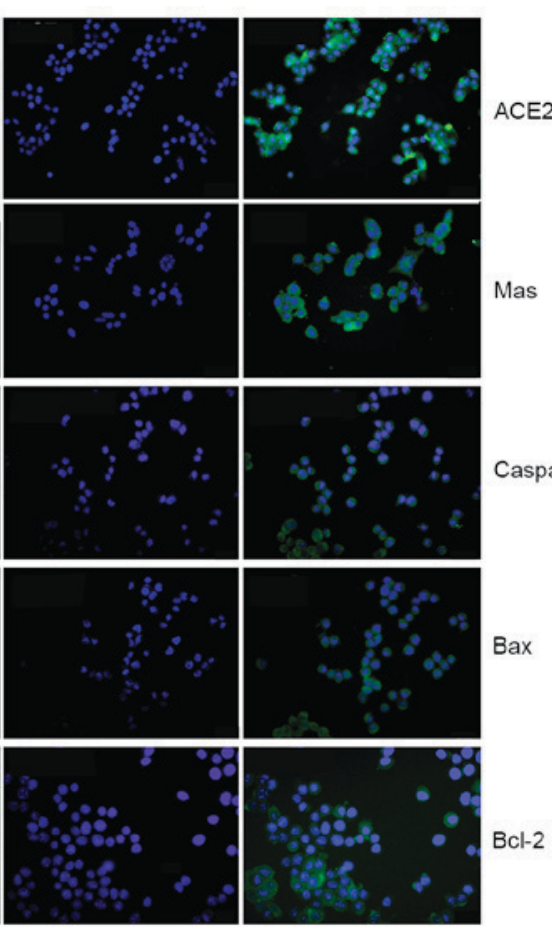

Nucleus

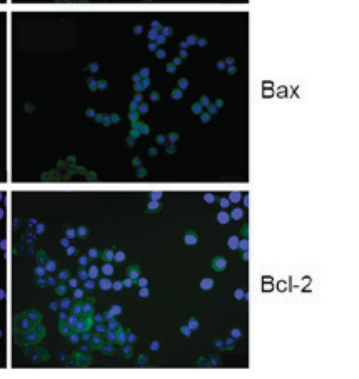

The whole cell

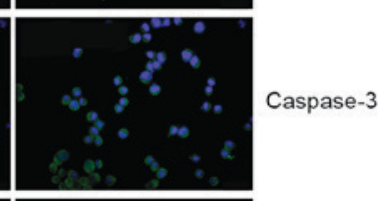

Figure 1. Fluorescence microscopy of cells stained with the specific monoclonal antibody immunofluorescence markers. Original magnification, x200. Green fluorescence represents target protein (left), blue represents nucleus (middle) and the integration of green and blue fluorescence signals represents the whole cell (right). ACE2, angiotensin-converting enzyme 2; Bax, Bcl-2-like protein 4; Bcl-2, B-cell lymphoma 2.

preincubated with different concentrations of Ang-(1-7) $\left(10^{-7}\right.$, $10^{-6}$ and $10^{-5} \mathrm{~mol} / \mathrm{l}$ ) for $30 \mathrm{~min}$. Soon afterwards the cleaved caspase-3, Bax and Bcl-2 protein levels were detected. As expected, the cleaved caspase- 3 protein levels reduced in a dose-dependent manner and reached the lowest level in the Ang-(1-7) $10^{-5} \mathrm{~mol} / \mathrm{l}$ group compared with the control and CAE groups ( $\mathrm{P}<0.05$; Fig. 4B). Fig. 4C demonstrates that $\mathrm{Bcl}-2$ and $\mathrm{Bax}$ had dose-dependent-rises $(\mathrm{P}<0.05)$. It is notable that the ratio of $\mathrm{Bax}$ to $\mathrm{Bcl}-2$ has a descending trend compared with the CAE and the control group, suggesting that Ang-(1-7) had anti-apoptotic potential (Fig. 4D).

A779 influences the expressing abilities of the cleaved caspase-3, Bax and Bcl-2. To investigate the possible protective effects of ACE2-Ang-(1-7)-Mas axis on CAE-induced pancreatic acinar cell apoptosis, the cells were pretreated with different concentrations of A779 $\left(10^{-7}, 10^{-6}\right.$ and $\left.10^{-5} \mathrm{~mol} / \mathrm{l}\right)$ for $30 \mathrm{~min}$ (Fig. 5). The A779 $10^{-6} \mathrm{~mol} / \mathrm{l}$ and $10^{-5} \mathrm{~mol} / 1$ groups demonstrated a significant increase of the cleaved caspase-3 protein level compared with the CAE group $(\mathrm{P}<0.05)$. In Fig. 5C and $\mathrm{D}$, it can be observed that while Bcl-2 and Bax increased in A779 group, the increase in the level of pro-apoptotic factor Bax was particularly pronounced compared with the anti-apoptotic factor Bcl-2. The ratio of them increased dose-dependently from $0.880 \pm 0.180$ (CAE group) to $1.285 \pm 0.179$ (A779 $10^{-5}$ group), $\mathrm{P}<0.05$. The results demonstrated that A779, Ang-(1-7) antagonist, possessed the potential to promote apoptosis. 
A

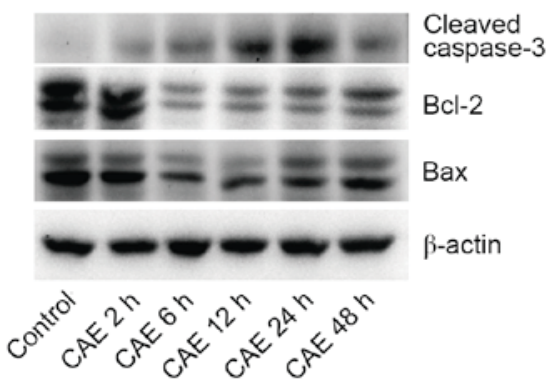

C

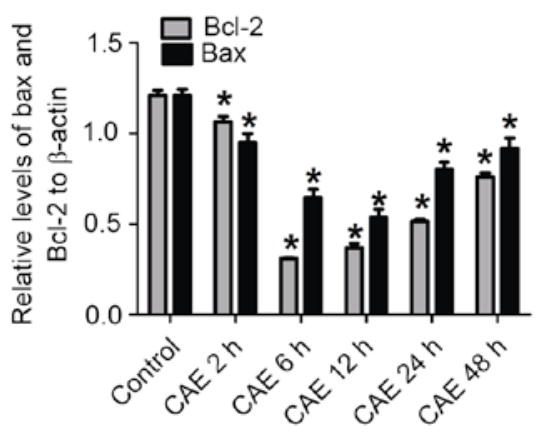

B

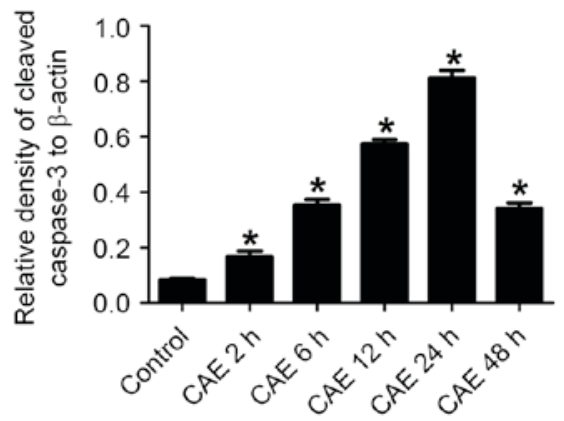

D

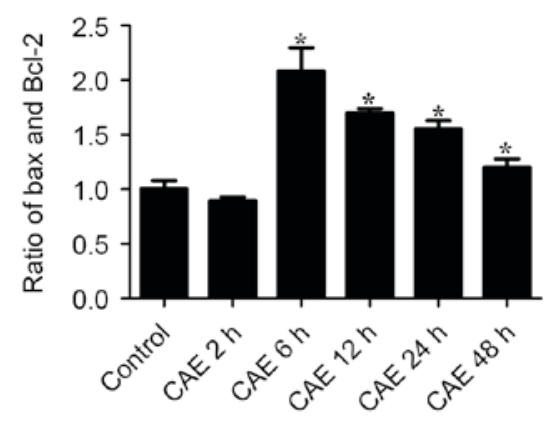

Figure 2. (A) Representative western blotting of the cleaved caspase-3, Bax, Bcl-2 and $\beta$-actin protein levels in the control and CAE groups. (B) Quantitative density of cleaved caspase-3 and (C) Bax and Bcl-2; the expression levels were normalized to $\beta$-actin in the control and CAE groups. (D) The dynamic ratio of Bax and Bcl-2 presented as a bar diagram. "P<0.05 vs. control group. Bax, Bcl-2-like protein 4; Bcl-2, B-cell lymphoma 2; CAE, caerulein.

A

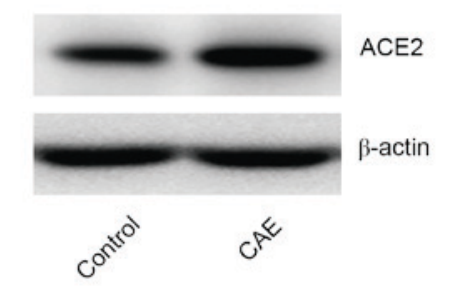

C

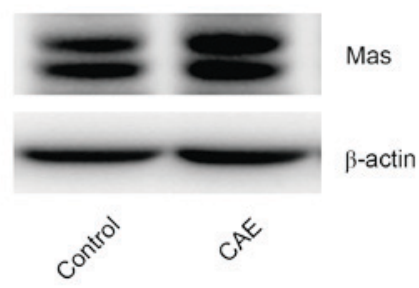

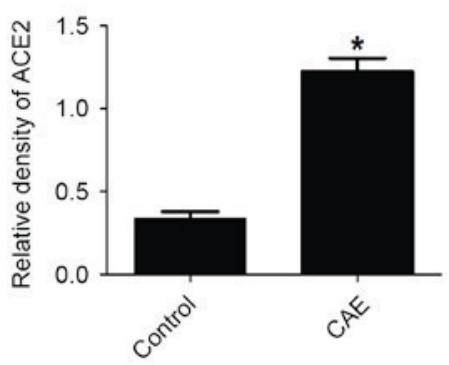

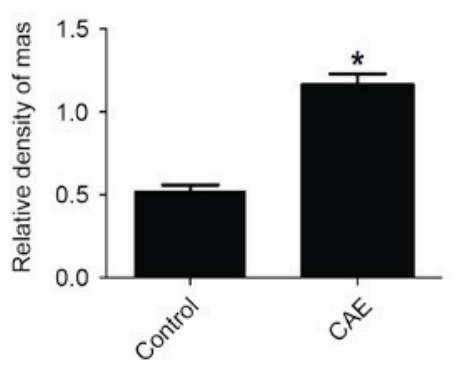

Figure 3. Representative western blotting and quantification of optical density of each band of (A and B) ACE2 and (C and D) Mas receptor in the control group and $\mathrm{CAE} 24 \mathrm{~h}$ group. ${ }^{*} \mathrm{P}<0.05$ vs. control group. ACE2, angiotensin-converting enzyme 2; CAE, caerulein.

\section{Discussion}

In the present study, immunofluorescence assays identified the presence of apoptotic factors in MPC-83 cells, including caspase-3 (particularly cleaved caspase-3), pro-apoptotic Bax and anti-apoptotic Bcl-2. It was observed that CAE upregulated the expression of cleaved caspase-3, which is an executioner in apoptosis. The ratio of Bax to Bcl-2, that is of pro-apoptotic to anti-apoptotic proteins, significantly decreased in the Ang-(1-7) group and increased in the A779 group. These results suggested that Ang-(1-7) may serve a distinct protective role in pancreatic acinar cell apoptosis in the process of AP.

The ACE2-Ang-(1-7)-Mas axis mediates a protective effect against the classic axis ACE-Ang II-AT1 in cardiovascular disease, arthritis, liver fibrosis and other diseases (22). Although there are a number of potential pathways in the formation of Ang-(1-7), it is suggested that that the conversion 
A

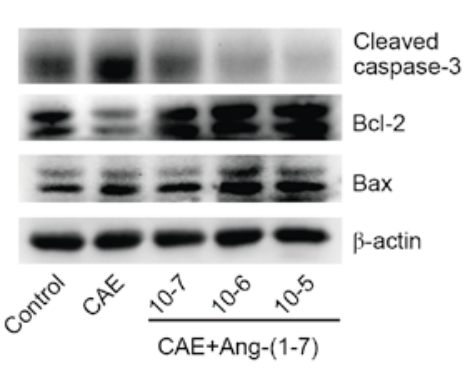

$\mathrm{C}$

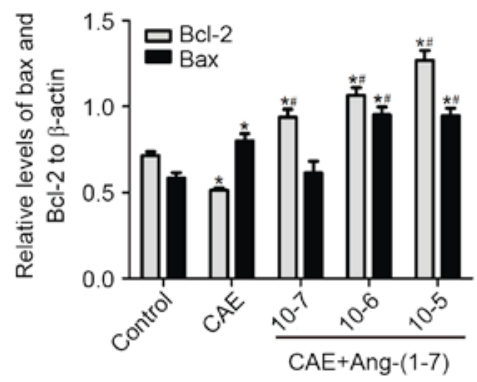

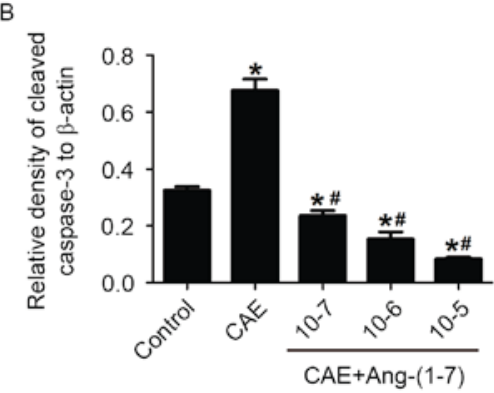

D

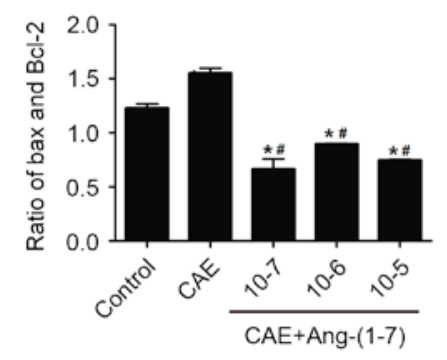

Figure 4. (A) Representative western blotting of the cleaved caspase-3, Bax, Bcl-2 and $\beta$-actin in the control group, CAE $24 \mathrm{~h}$ group and CAE + Ang-(1-7) groups $\left(10^{-7}, 10^{-6}\right.$ or $\left.10^{-5} \mathrm{~mol} / \mathrm{l}\right)$. Quantification of (B) cleaved caspase-3 and (C) Bax and Bcl-2 protein contents; expression levels were normalized to $\beta$-actin. (D) The ratio of Bax and Bcl-2 presented as a bar diagram. ${ }^{~} \mathrm{P}<0.05$ vs. control group; ${ }^{~} \mathrm{P}<0.05 \mathrm{CAE}+$ Ang-(1-7) group vs. CAE $24 \mathrm{~h}$ group. Bax, Bcl-2-like protein 4; Bcl-2, B-cell lymphoma 2; CAE, caerulein; Ang-(1-7), angiotensin-(1-7).

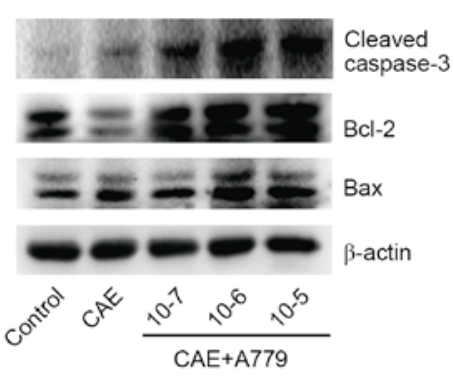

C

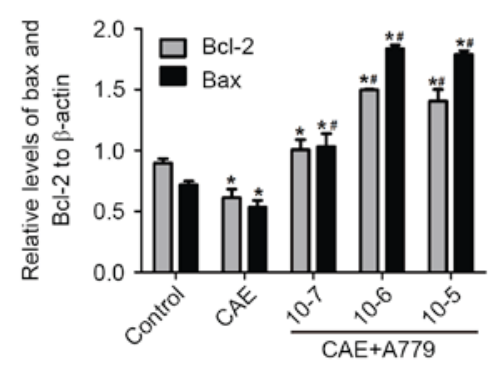

B

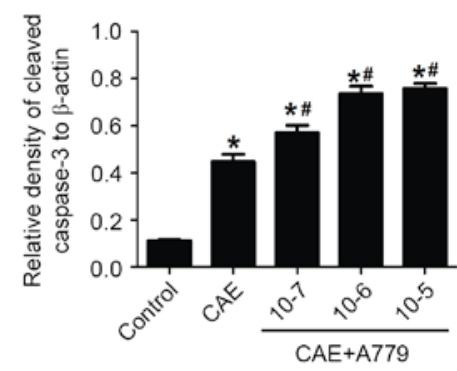

D

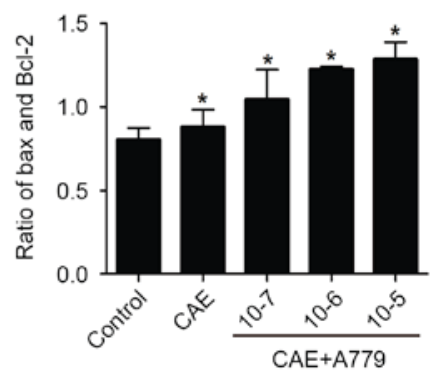

Figure 5. (A) Representative western blotting of the cleaved caspase-3, Bax, Bcl-2 and $\beta$-actin in the control group, CAE group and CAE + A779 groups (10 ${ }^{-7}$, $10^{-6}$ or $\left.10^{-5} \mathrm{~mol} / \mathrm{l}\right)$. Quantification of (B) cleaved caspase-3 and (C) Bax and Bcl-2; the protein levels were normalized to $\beta-$ actin. (D) The ratio of Bax and Bcl-2 presented as a bar diagram. ${ }^{*} \mathrm{P}<0.05$ vs. control group; ${ }^{*} \mathrm{P}<0.05 \mathrm{CAE}+\mathrm{A} 779$ group vs. CAE group. Bax, Bcl-2-like protein 4; Bcl-2, B-cell lymphoma 2; CAE, caerulein; A779, angiotensin-(1-7) antagonist.

of Ang II to Ang-(1-7) by ACE2 is the primary physiological pathway for Ang-(1-7) production (23). ACE2 may serve an important counter regulatory role in the RAS pathway, protecting cells from Ang II-mediated injury by inhibiting its production, improving degradation rate and accelerating its conversion to Ang-(1-7) (24). Therefore, it was hypothesized that the upregulation of ACE2 and Mas in AP MPC-83 cells may represent a protective response against the functions of ACE and Ang II.

A previous study demonstrated that ACE2 and Mas receptor protein levels were upregulated in CAE-induced pancreatic acinar cells (25). We also previously identified that ACE and ACE2 increased in acinar cells in SAP mouse models, the imbalance between ACE and ACE2 possibly 
contributing to pancreas injury by intensifying the severity of pancreatitis (26). In the present study, the ACE2-Ang-(1-7-Mas axis (the non-classical RAS axis)-associated proteins of ACE2 and Mas receptor level demonstrated a significant increase in CAE-induced pancreatic acinar cells and Ang-(1-7) was able to curb cleaved caspase-3 protein expression and increase the anti-apoptotic factor $\mathrm{Bcl}-2$ faster than the pro-apoptotic factor Bax, suggesting that Ang-(1-7) possessed anti-apoptotic potential. A779 was able to improve cleaved caspase-3 protein level and enabled the pro-apoptotic factor Bax to increase more than the anti-apoptotic factor Bcl-2. The results demonstrated that Ang-(1-7) possessed the potential to inhibit apoptosis and protect the pancreas from damage. These data, together with a previous study (27), demonstrated that exogenous Ang-(1-7) may affect the balance of Ang-(1-7)/Ang II in addition to ACE2/ACE in AP. This is also consistent with previous animal experiments; that identified that ulinastatin significantly ameliorated pancreatic pathology through upregulating ACE2 and Ang (1-7) in addition to the serum biochemistry indicators of CAE-induced SAP mice (28). The re-establishment of the balance of RAS through upregulating Ang-(1-7) and ACE2 expression, which can ameliorate apoptosis, may possess clinical therapeutic potential.

The observations of the current study may provide evidence for the design of specific and powerful anti-apoptotic agents that function by attenuating AP. The vast array of molecules involved in apoptotic and necrotic pathways offer a number of attractive therapeutic target sites. Considering the possibly important role of Ang-(1-7) in pancreatic acinar cell apoptosis, efforts should be made to exploit clinical strategies targeted to the regulatory axis by taking adoptable methods including upregulating the expression of ACE2 and/or Ang-(1-7).

\section{Acknowledgements}

The present study was supported by the Beijing Natural Science Foundation (2014; grant no. 7142044) and the National Natural Science Foundation of China (2016; grant no. 81571933).

\section{References}

1. Liu B, Huang $\mathrm{J}$ and Zhang B: Nobiletin protects against murine 1-arginine-induced acute pancreatitis in association with downregulating p38MAPK and AKT. Biomed Pharmacother 81: 104-110, 2016

2. Fu Q, Qin T, Chen L, Liu CJ, Zhang X, Wang YZ, Hu MX, Chu HY and Zhang HW: miR-29a up-regulation in AR42J cells contributes to apoptosis via targeting TNFRSF1A gene. World J Gastroenterol 22: 4881-4890, 2016.

3. Cai Y, Shen Y, Xu G, Tao R, Yuan W, Huang Z and Zhang D: TRAM1 protects AR42J cells from caerulein-induced acute pancreatitis through ER stress-apoptosis pathway. In Vitro Cell Dev Biol Anim 52: 530-536, 2016.

4. Yuan J, Liu Y, Tan T, Guha S, Gukovsky I, Gukovskaya A and Pandol SJ: Protein kinase d regulates cell death pathways in experimental pancreatitis. Front Physiol 3: 60, 2012.

5. Ashour AE, Ahmed AF, Kumar A, Zoheir KM, Aboul-Soud MA, Ahmad SF, Attia SM, Abd-Allah AR, Cheryan VT and Rishi AK: Thymoquinone inhibits growth of human medulloblastoma cells by inducing oxidative stress and caspase-dependent apoptosis while suppressing NF- $\kappa \mathrm{B}$ signaling and IL-8 expression. Mol Cell Biochem 416: 141-155, 2016.

6. Chen K, Chu BZ, Liu F, Li B, Gao CM, Li LL, Sun QS, Shen ZF and Jiang YY: New benzimidazole acridine derivative induces human colon cancer cell apoptosis in vitro via the ROS-JNK signaling pathway. Acta Pharmacol Sin 36: 1074-1084, 2015.
7. Mareninova OA, Sung KF, Hong P, Lugea A, Pandol SJ, Gukovsky I and Gukovskaya AS: Cell death in pancreatitis: Caspases protect from necrotizing pancreatitis. J Biol Chem 281: 3370-3381, 2006

8. Nuche-Berenguer B, Ramos-Álvarez I and Jensen RT: Src kinases play a novel dual role in acute pancreatitis affecting severity but no role in stimulated enzyme secretion. Am J Physiol Gastrointest Liver Physiol 310: G1015-G1027, 2016.

9. Kobayashi C, Yaegaki K, Calenic B, Ishkitiev N, Imai T, Ii H, Aoyama I, Kobayashi H, Izumi Y and Haapasalo M: Hydrogen sulfide causes apoptosis in human pulp stem cells. J Endod 37: 479-484, 2011.

10. Ondroušková E and Vojtěšek B: Programmed cell death in cancer cells. Klin Onkol 27 (Suppl 1): S7-S14, 2014 (In Czech).

11. Abogresha NM, Greish SM, Abdelaziz EZ and Khalil WF: Remote effect of kidneyischemia-reperfusion injury on pancreas: Role of oxidative stress and mitochondrial apoptosis. Arch Med Sci 12: 252-262, 2016.

12. Gaddam RR, Ang AD, Badiei A, Chambers ST and Bhatia M: Alteration of the renin-angiotensin system in caerulein induced acute pancreatitis in the mouse. Pancreatology 15: 647-653, 2015.

13. Ibiş M, Yüksel O, Yilmaz G, Köklü S, Yilmaz FM, Ertuğrul I, Uçar E and Altiparmak ME: Serum angiotensin converting enzyme levels in pancreatic diseases. Hepatogastroenterology 55: 1814-1817, 2008.

14. UlmasovB,XuZ,TalkadV,OshimaKandNeuschwander-TetriBA: Angiotensin II signaling through the AT1a and AT1b receptors does not have a role in the development of cerulein-induced chronic pancreatitis in the mouse. Am J Physiol Gastrointest Liver Physiol 299: G70-G80, 2010.

15. Colafella KM, Hilliard LM and Denton KM: Epochs in the depressor/pressor balance of the renin-angiotensin system. Clin Sci (Lond) 130: 761-771, 2016.

16. Wang J, Liu R, Qi H, Wang Y, Cui L, Wen Y, Li H and Yin C: The ACE2-angiotensin-(1-7)-Mas axis protects against pancreatic cell damage in cell culture. Pancreas 44: 266-272, 2015.

17. Gopallawa I and Uhal BD: Angiotensin-(1-7)/mas inhibits apoptosis in alveolar epithelial cells through upregulation of MAP kinase phosphatase-2. Am J Physiol Lung Cell Mol Physiol 310: L240-L248, 2016.

18. Uhal BD, Li X, Xue A, Gao X and Abdul-Hafez A: Regulation of alveolar epithelial cell survival by the ACE-2/angiotensin 1-7/Mas axis. Am J Physiol Lung Cell Mol Physiol 301: L269-L274, 2011.

19. Uhal BD, Nguyen H, Dang M, Gopallawa I, Jiang J, Dang V, Ono $\mathrm{S}$ and Morimoto K: Abrogation of ER stress-induced apoptosis of alveolar epithelial cells by angiotensin 1-7. Am J Physiol Lung Cell Mol Physiol 305: L33-L41, 2013.

20. Ma X, Xu D, Ai Y, Zhao S, Zhang L, Ming G and Liu Z: Angiotensin-(1-7)/Mas signaling inhibits lipopolysaccharide-induced ADAM17 shedding activity and apoptosis in alveolar epithelial cells. Pharmacology 97: 63-71, 2016.

21. Yu JH, Lim JW and Kim H: Altered gene expression in cerulein-stimulated pancreatic acinar cells: Pathologic mechanism of acute pancreatitis. Korean J Physiol Pharmacol 13: 409-416, 2009.

22. da Silveira KD, Coelho FM, Vieira AT, Sachs D, Barroso LC, Costa VV, Bretas TL, Bader M, de Sousa LP, da Silva TA et al: Anti-inflammatory effects of the activation of the angiotensin-(1-7) receptor, MAS, in experimental models of arthritis. J Immunol 185: 5569-5576, 2010.

23. Gallagher PE and Tallant EA: Inhibition of human lung cancer cell growth by angiotensin-(1-7). Carcinogenesis 25: 2045-2052, 2004.

24. Ohishi M, Yamamoto K and Rakugi H: Angiotensin (1-7) and other angiotensin peptides. Curr Pharm Des 19: 3060-3064, 2013.

25. Wang Y, Wang J, Liu R, Qi H, Wen Y, Sun F and Yin C: Severe acute pancreatitis is associated with upregulation of the ACE2-angiotensin-(1-7)-Mas axis and promotes increased circulating angiotensin-(1-7). Pancreatology 12: 451-457, 2012.

26. Liu R, Qi H, Wang J, Wang Y, Cui L, Wen Y and Yin C: Angiotensin-converting enzyme (ACE and ACE2) imbalance correlates with the severity of cerulein-induced acute pancreatitis in mice. Exp Physiol 99: 651-663, 2014.

27. Wang J, Liu R, Qi H, Wang Y, Cui L, Wen Y, Li H and Yin C: The ACE2-angiotensin-(1-7)-Mas axis protects against pancreatic cell damage in cell culture. Pancreas 44: 266-272, 2015.

28. Liu R, Qi H, Wang J, Wang Y, Cui L, Wen Y and Yin C: Ulinastatin activates the renin-angiotensin system to ameliorate the pathophysiology of severe acute pancreatitis. J Gastroenterol Hepatol 29: 1328-1337, 2014. 